\title{
PECULIARITIES OF APPLYING COACHING AS A TOOL FOR RAISING PERFORMANCE OF EDUCATION IN SOUTHERN-RUSSIAN INSTITUTE OF MANAGEMENT \\ Victoria Nekrasova $^{1}$, Veneta Baeva $^{2}$, Natatalya Kovalenko ${ }^{3}$
}

\begin{abstract}
The practice of using the educational potential of undergraduates, in contemporary scholastic institutions, reflects the insufficient effectiveness of using knowledge as a necessary component of forming graduates' professional human capital. On the one hand, students' abilities are realized at a lower level than possible. On the other hand, the available educational potential is limited to performing certain training tasks in a framework with competencies that lead to a falling quality of education and consequently, to the decreasing competitiveness of a high school.
\end{abstract}

UDC Classification: 376; DOI: http://dx.doi.org/10.12955/cbup.v6.1231

Keywords: coaching, educational program, coach, trainer, trainee.

\section{Introduction}

Classic and innovative methods of teaching and developing students are oriented towards the growth of quality education, achievement of goals for the teaching program of the discipline, as well as developing the competitive and professional human capital of undergraduates in the labor market. On applying such methods the achievement of an educational 'match' is advanced.

An educational match reflects the suitability of a single student from the point of view of their educational competence (competence on the level of forming professional human capital in the discipline of study). This is based on the requirements of the discipline's program. The grade of suitability for these requirements is defined as indicators and criteria for assessment at the level of mastered competencies.

The rate of a student's educational potential indicates the degree of their suitability under requirements of the discipline's program, as reflected in these levels: 1) full or part mismatch, 2) full match, 3) over match (match overstating the requirements). The last variant, 'over match', reflects the education potential level of an over competent student where the student's abilities are not fully engaged in the learning process. That is, it is not favorable to the student because their over competence furthers them to solve more comprehensive tasks. 'Mismatch' reflects the degree of mastering the discipline's program below the required level. Where necessary, the educational match (or mismatch) can be estimated for a group of students involved in a continuous training cycle or interrelated with solving general problems in the concrete stage of mastering the discipline or for a team executing the project.

\section{Coaching Advantages}

The lecturer (tutor) can constructively settle the problem of developing professional human capital among students with different competence levels. One alternative is called 'continuous training', where students who have not fully mastered the educational program are trained by those who have studied the discipline program successfully. This uses an approach based on competencies. The first group of students is classed as 'students subject to training' or 'trainees' and the latter as training students or trainers (coaches).

In terms of scientific education, the interest lies in a 'continuous training' that is the most advantageous and profitable for all participants involved in the training, for these reasons:

- It is relatively economical. Cost is calculated based on a lecturer's (tutor's) time on performed tasks;

- The student's involvement in the training and social interrelation grows;

- It provides direct feedback to the students who are subject to the training; and

- It has potential as a tool of self-career management and self-professional development for the trainer (coach).

\footnotetext{
${ }^{1}$ Department of Management, Southern-Russian Institute of Management, vikanekrasova@yandex.ru

2 Department of Management, Southern-Russian Institute of Management, baeva_vd@mail.ru

${ }^{3}$ Department of Management, Southern-Russian Institute of Management, sonatak96@gmail.com
} 
The described sequence of developing student's professional human capital is successfully fulfilled through training techniques.

It is important to define the distinction between learning and training. According to Armstrong (2009), learning is considered a process promoting the person to obtain new knowledge, skills, and capabilities; whereas training is considered as one of several responses an organization can undertake to promote learning.

Armstrong (2009) specifies the following types of training:

- Manual skills, including modern apprenticeship;

- Information and technology (IT) skills;

- Team leader or supervisory training:

- Management training;

- Interpersonal skills, e.g. leadership, team-building, group dynamics, neuro-linguistic programming;

- Personal skills, e.g. assertiveness, coaching, communicating, time management; and

- Training in organizational procedures or practices, e.g. induction, health and safety, performance management, equal opportunity or managing diversity policy and practice.

One of the most convenient training methods in education is coaching. This method of informal training is widely used in the Southern-Russian Institute of Russian Presidential Academy of National Economy and Public Administration.

Under the most common definition, coaching is a method of professional development. German scientists, Wöhe and Dyoring (2010) considered coaching in the framework of a business (plant, factory). The workers are directed on how to effectively carry out their current tasks and grow professionally by the trainer (coach). A 'linear' manager who performs orienting, consulting, training, and leading, is a coach. The aim of coaching is raising workers' professional skills.

Coaching is a personal (usually one-to-one) on-the-job approach to helping people develop their skills and levels of competence. A structured and purposeful dialogue is the focal point of coaching. The coach uses feedback and provides an objective perspective. The need for coaching may arise from formal or informal performance reviews, but opportunities for coaching will emerge during normal day-to-day activities (Armstrong, 2009).

From a point of learning, coaching is a method to stimulate professional promotion. In the framework of coaching, students are directed on how to effectively carry out their training tasks and to develop professional capital with the assistance of a coach. The students who have successfully mastered competencies of the discipline's program and are motivated by self-development as a professional can then act as coaches. In teaching the trainee, the coach (trainer) raises their professional capital. As a result, all participants involved in coaching have these advantages:

1. The student (trainer, coach) develops further and raises their professional human capital;

2. The student subject to training (trainee) achieves efficiency indicators (indicators and criteria for assessment on the level of mastered competencies) and develops their professional capital through an individual approach provided to them by another trainee; and

3. The lecturer (tutor) uses less time to explain tasks by delegating certain powers to the coach; the trainee masters tasks in the framework of the discipline's program to the required level.

\section{The Coaching Sequence in Southern-Russian Institute of Management}

The following explains the practical aspect of coaching application among students of SouthernRussian Institute of Management (SRIM) who master educational program in Management.

For example, in the discipline, 'business planning', the coach can train the trainee (or trainees) in techniques to calculate Front-End-Investments (FEI) and Break-Even-Point (BEP). The first stage in the coaching defines the problem. A typical problem is where a student fails to understand how they can calculate FEI and BEP. There are various factors that prevent such an understanding. These include a student's absence from lessons because of illness or social events. The reasons themselves are less important than the result of having students who fail to perform the calculations and the 
lecturer (or tutor) needing to explain the units in the discipline's program. This is a problem for the lecturers. To resolve this, the student undertaking the training needs to understand how to properly perform the following:

- To calculate the amount of FEI;

- To form the sequence of calculating BEP; and

- To calculate BEP according to the built sequence.

The following is an example of coaching performed by students of the SRIM.

The first meeting of the coach with the trainee helped determine whether the student accepting the training was motivated or not towards it. On the first encounter, the student appeared motivated to source and understand the calculating methods. The student sought to perform the tasks and proceed with the exam but was not interested in studying the material. To stimulate the student's interest, in the first stage of coaching, the coach began by encouraging them with by offering them additional points and the benefits of studying for the exam (according to the previous agreement with the lecturer). At the same time, the coach spoke of their own motivation and where they had accepted additional points and resolved 'mismatches'. The coach at times had 'mismatches' because of work and lack of enthusiasm to master the educational program on the required level.

The coach's openness on gaining additional points provided the necessary motivation (the coach applied the approach specifically to this student). In the first lesson, the coach simply explained the formula, showing the figures, and where to place them. However, by the second meeting, the coach recognized the lack of prospects of this approach in that the trainee could not recall earlier explanations nor repeat the operations they had previously performed. The coach understood that it was necessary to provide an understanding of the material in addition to showing the mechanics of the operations.

After the first meeting, the coach understood, the student (trainee) could not calculate the task because of a lack of basic understanding of business processes, market laws, logic laws, and interrelationships. The formula written by the student was not in accordance with that required of the question asked. The student could not apply the formula. The necessary student's understanding of the relationship between the formula and skills to apply it or the knowledge and skills from other branches necessary to apply it, on first sight as a simple formula, was absent.

The considered sequence had the required effect specifically for this student. While it could work for students with similar motivational issues, it may be unsuitable for others. The suitability of certain coaching tools can differ for each person.

In the given example, the reason preventing the trainee from understanding the essence of the question was determined. Before starting to explaining the subject and the question for teaching the operations, corrections were implemented. Therefore, this agrees with Armstrong's view (2009), that coaching will be most effective when the coach understands that his or her role is to help people to learn and individuals are motivated to learn.

The described coaching is fulfilled through cognitive and experimental learning (Armstrong, 2009). According to Armstrong (2009), cognitive learning theory involves gaining knowledge and understanding by absorbing information in the form of principles, concepts, and facts and then internalizing it. Learners can be regarded as powerful information processing machines.

On experiential learning theory, Armstrong (2009) stressed that people are active agents of their own learning. Experiential learning takes place when people learn from their experience by reflecting on it so that it can be understood and applied. Learning is, therefore, a personal 'construction' of meaning through experience. 'Constructivists' such as Rogers (1983) believe that experiential learning will be enhanced through facilitation creating an environment in which people can be stimulated to think and act in which people can be stimulated to think and act in ways that help them to make good use of their experience.

Therefore, cognitive learning and experiential learning can be used as coaching methods. These methods are widely applied by teaching students (coaches, trainers) in coaching students who are undertaking training (trainees).

Coaching, using the above-stated methods in SRIM, is built on a sequence, as shown in Figure 1. 


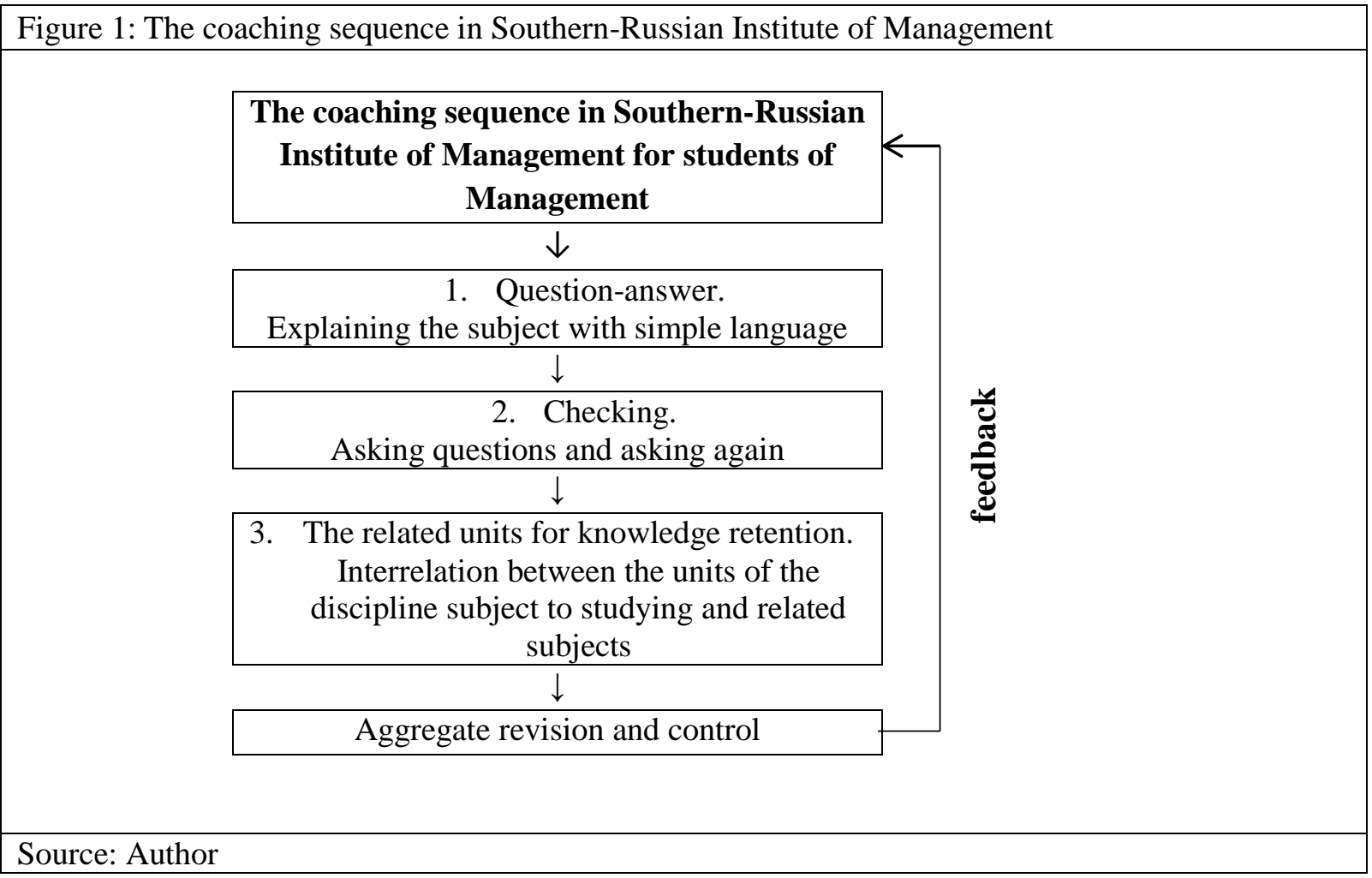

The following considers each of the four coaching stages in details.

First, there is the question and answer stage, which is about explaining the essence of the subject using simple language (in most cases it is the first lesson, i.e., the first training).

The coach begins by explaining the basic components of the formula. In this, it is important to use simple language and at the same time, interrelate with the student. This includes commenting on definitions with practical examples. In common meetings, the coach first asks about a component, without explanation. This approach helps to establish the student's understanding of the subject and where additional comments are needed. Where the trainee lacks a clear understanding, the coach explains further, starting with basic components and definitions. For example, the coach clarifies further, with simple examples, the principle of distributing the fixed and variable costs to all involved in starting a business.

In this example, the first step is the question, which asks 'what is fixed and variable costs?'

The second step is improving the student's understanding and then asking them to repeat the subject. This follows the principle of feedback.

The third step is where some inaccuracies are noticed. Improvements are suggested with clear reasons as to why it is a certain way and not otherwise.

The fourth step is general questioning where the coach asks the trainee to classify all costs and explain why the trainee related certain costs to fixed and others to variable.

The suggested approach allows the trainee to master the material, not by rote learning, but by understanding the subject, e.g., why the formula is a certain way and not otherwise. It develops the trainee to apply knowledge not only in the particular task but in professional practice as a whole.

Second in the sequence is the checking stage where the trainee asks questions until they understand. This is known as purification and in most cases, it occurs in the second lesson, i.e. a second training. The trainee asks the questions and where they do not understand, they ask again. For most trainees, it is an important achievement for these reasons:

1. The trainees who are primarily oriented towards material stimulus (i.e. to obtain points and take an exam) gradually lose interest in it. It is possible for the coach to explain the essence of the subject as a routine in life or work activity and on this basis, motive the subject (in the above example it is about the discipline of 'business planning'); and 
2. Through leading questions, the trainees begin to master the subject. Through leading questions, the gaps are determined and the teaching methods that help to eliminate the gaps are chosen. Thus, the base for gaining further knowledge is formed.

The third stage refers to the related units for retaining knowledge. This stage involves interrelating the units and the corresponding subjects of the studied discipline (in most cases, in the second and following training). For example, in describing the labor payment principles, it is necessary to delve into motivation theories and explain why there is no need for a form for workers who receive payment at the fixed remuneration rate. By completing gaps in knowledge relating to other disciplines, a complex understanding of business planning is formed. On this basis, the trainees can recognize the interrelationship of business planning with other disciplines and practical situations in routine life. They form an integrated picture and understanding on how to apply this knowledge in practice. A calculation without understanding the material is unwise because, like the students considered in the article, who studied Management, trainees need to see the general picture and apply the scientific methods of deduction and induction.

The control of results and explanations of related disciplines is the final and necessary step in the sequence. Success is reached when the trainees begin to understand elementary components of business planning and comprehend the interrelationship of this discipline with other subjects and professional practice.

This fourth stage is an aggregate of revision and of control (the last training). The aggregate result of the training is that the trainees can calculate the task, analyze the situation, and form the calculation sequence. While it is evident that the trainees are not valuable specialists for some training (coaching lessons), they are clearly confident in drawing conclusions and understanding and applying acquired skills, not only in a certain task but in other assignments and situations.

\section{Conclusion}

In coaching, the coach understands that the trainee needs to form a general understanding and equips them with guide. In certain cases, the guides, which are instructions containing the prepared sequence of operations, help, but in other cases, they assist with skills in the mechanics but fail to provide the trainee with an understanding, i.e., the student (the trainee) can only apply the acquired knowledge in typical tasks. Thus, where the tasks differ from those that are typical, the trainee falters. Whereas, the trainee that gains a complex understanding of the subject comprehends it much better. The most conclusive role in coaching is performed by the lecturer (tutor) of a discipline, who plans the coaching tasks according to the discipline's educational program.

\section{References}

Armstrong M. (2009). Armstrong's Handbook of Human Resource Management Practice Kogan Page.

Rogers K. (1983). Freedom to learn for the 80s. Columbus, OH, Charles E. Merrill.

Wöhe, G. and Döring, Ul. (2010), Einführung in die Betriebswirtschaftslehre, Verlag Franz Vahlen, München. 